BMJ Open Sport \& Exercise Medicine

\title{
Sports injuries and illnesses during the Granada Winter Universiade 2015
}

\author{
Miguel Ángel Gallo-Vallejo, ${ }^{1}$ Juan Carlos de la Cruz-Márquez, ${ }^{2}$ \\ Adrián de la Cruz-Campos, ${ }^{2}$ Juan Carlos de la Cruz-Campos, ${ }^{2}$ \\ Francisco Luis Pestaña-Melero, ${ }^{2}$ Ginés Carmona-Ruiz,, ${ }^{2}$ Luz María Gallo-Galán ${ }^{3}$
}

To cite: Gallo-Vallejo MÁ, de la Cruz-Márquez JC, de la Cruz-Campos A, et al. Sports injuries and illnesses during the Granada Winter Universiade 2015. BMJ Open Sport Exerc Med 2017;2: e000123. doi:10.1136/ bmjsem-2016-000123

- Prepublication history and additional material is available. To view please visit the journal (http://dx.doi.org/ 10.1136/bmjsem-2016000123).

Received 08 February 2016 Revised 10 August 2016 Accepted 10 August 2016

\section{CrossMark}

\footnotetext{
${ }^{1}$ Sports Medicine Centre of Granada City Council, Granada, Spain ${ }^{2}$ Department of Physical Education and Sport, Faculty of Sport Sciences, University of Granada, Granada, Spain ${ }^{3}$ University of Cantabria (Spain) Granada, Granada, Spain
}

Correspondence to Dr Adrián de la CruzCampos; adlcruz86@gmail. com

\section{ABSTRACT}

Objective: To analyse the incidence of diseases and injuries suffered by athletes participating in the 27th Winter Sports Universiade held in Granada, Spain. Methods: The daily occurrence of injuries and diseases was registered at the point of first aid (Borreguiles, 2665 metres above sea level (masl)) and in the clinic of Pradollano (2017 masl), both in Sierra Nevada, as well as in medical services provided by the organising committee of Granada 2015 Universiade and located in sport pavilions in which indoor competitions are held

Results: A total of 1109 athletes (650 men, $58.61 \%$; 459 women, $41.39 \%$ ). Nine diseases and 68 injuries were recorded. In total, the rate of injury was $6.13 \%$ ( $7.07 \%$ for men and $4.79 \%$ for women). The percentage of injury was highest in alpine skiing $(10.34 \%)$ followed by freestyle skiing $(8.62 \%)$. In relation to the time of exposure, freestyle skiing showed the shortest time of exposure ( 0.31 hours) before suffering an injury. Short track speed skating showed the longest exposure ( 9.80 hours), before suffering an injury. The most common anatomical areas of injury were the head, shoulder and knee $(13.23 \%)$. Only nine diseases were suffered (four women and five men) of which six were infections, one was a friction burn, one was a lipothymy and one a cluster headache due to height.

Conclusion: In general, $6.13 \%$ of the athletes sustained at least one injury and $0.81 \%$ a disease, which is a much lower percentage than that recorded in similar events. The incidence of injuries and diseases varied among sport specialities.

\section{INTRODUCTION}

High-level sport involves physical and psychological overexertion that can have a negative impact on the welfare of the athlete. ${ }^{1}$ Participants in the Universiade range between 18 and 28 years of age, so it is crucial to prevent sport injuries that could limit their future sporting participation. ${ }^{2}$

University-level events help to ensure similar age and skill levels between participants who contributes to a fair contest and less risk of injury due to large variances in body morphology or skill level. ${ }^{3}$ It is of utmost importance to obtain data on the

\section{What are the new findings?}

- The incidence of injuries in 2015 Winter Universiade Granada is lower with respect to other similar winter international events.

- An injury index (II) between the total practical exposure time and the number of injuries by modality has been determined.

- The more affected anatomical areas were the head, right shoulder and hand, followed by the left knee and ankle.

- The modality with high II was freestyle skiing, which presents a injury each 0.31 hours.

risk of injury and illness among elite young athletes, as they may counteract the beneficial effects of participating in sport at an early age, in the case that a teenager cannot continue participating due to residual effects of an injury or a chronic illness. ${ }^{3}$

When holding a major sporting events, the actions of monitoring and analysing the athletes are recognised to be very important to reduce the occurrence of injuries and diseases. ${ }^{4}$ The efficiency of the application of different methods of prevention of injury at the Vancouver 2010 Winter Olympic Games has been demonstrated. ${ }^{5}$

There are few studies on epidemiological data obtained in major international winter sports events, where environmental and changing weather conditions can influence the occurrence of injuries and diseases. A similar study was undertaken during the First Youth Olympic Winter Games (Innsbruck, Austria, 2012). ${ }^{6}$ There are also studies on the incidence of injury in highlevel winter athletes with much wider age ranges. ${ }^{7-11}$

The objective of the present study was to analyse and describe the injuries and diseases suffered during the 27th Winter Sports Universiade held in February 2015 in Granada and Sierra Nevada, Spain. We are confident that the data gained from the 
study will be able to improve upon current practices of reducing the risk of injury and illness in future major sporting events, as the monitoring of illnesses and injuries is the first step in the prevention of these. ${ }^{12}$

\section{METHODS}

Sports modalities that took place at the Winter Sports Universiade (2015) were: alpine skiing, snowboarding, freestyle skiing, figure skating, curling, ice hockey and short track speed skating. The medical care records were collected from these modalities. For technical reasons, the cross-country skiing, Nordic combined, ski jumping and biathlon competitions were held in Slovakia. The rest of modalities were held in Granada, Spain.

The medical committee and health staff of the Universiade recorded the daily incidence of all injuries and illnesses that occurred in each of the sport disciplines. Data were collected for injuries and illnesses sustained during training and competition.

Also, there was a follow-up on the diagnosis of the athletes who were treated in hospitals. All the injuries were registered in the case of multiple incidents in which various parts of the body were involved.

\section{Implementation}

Prior to the start of competitions, the medical committee reported to the medical leaders of delegations from all participating countries the details of the healthcare system, control points and assistance delivery, and reference hospitals in case of evacuation.

At the outdoor competitions (alpine skiing, snowboarding and freestyle skiing), there was a medical team on track with an ambulance, a mobile intensive care unit (ICU), a first aid point located in Borreguiles (2665 metres above sea level (masl)), and a complete medical clinic located in Pradollano (2017 masl), equipped with four boxes of diagnosis tools and full assistance and an observation and stabilisation unit with three beds equipped with radiological installations. These teams medically stabilised the athletes before sending them to hospital, where the final diagnosis of the injuries and illnesses took place.

Figure skating, curling, ice hockey and short track speed skating were held indoor in Granada (683 masl). Each covered pavilion had a medical team during training sessions and the competitions of each sport. They also had a mobile ICU and back-up medical staff.

In the case of an accident or an illness, a standard control form was used in which the athlete's personal data were reflected. This standard control form contains several items as age, sex, nationality, sport, the injury type suffered, the treatment applied and the state of the athlete after the assistance, taking into consideration whether he could return to the competition or was sidelined for the event. The injury diagnosis was made by doctors specialising in orthopaedic surgery, sports medicine and emergency medicine.

\section{Definition of injuries and diseases}

All medical attention that prevented the athlete's participation in each of the sport modalities has been considered as an injury or a disease, as in similar articles. $^{13}$

The information collected was: sport and sport discipline, athlete's sex, injury type, place and date of the event.

\section{Confidentiality and ethic committee}

Medical and personal data have been kept by the medical officer and treated according to the current regulations in the Spanish state and in compliance with the organic law 15/1999, of December 13, to maintain their confidentiality and privacy. These data have not been used for any other purpose and will be destroyed once past the time established by law. The approval of the ethic committee of Granada University has been also obtained (with registration number 22/CEIH/2015).

\section{Data analysis}

Practical exposure time (Pext) of participations has been calculated according to speciality and sex. In alpine skiing, short track speed skating and snowboarding, the official timings published by the Official Committee of Judges and Timekeepers designated by the Fédération Internationale du Sport Universitaire (FISU) have been recorded.

In ice hockey and figure skating, the execution time indicated in the rules of the competition was taken into consideration.

And finally, in the specialities of curling and freestyle skiing (score sports), a systematic observation was performed, resulting in a total Pext of each participant in both disciplines.

In each sport, the average exposure time has been calculated, obtained by the sum of the participants' time and their relationship with the number of participations in each speciality. The number of participations has been defined as the number of times that an athlete is involved in competition.

$$
\operatorname{Pext} \bar{X}=\sum \operatorname{Pext} / \mathrm{n}
$$

After obtaining the average exposure time, the risk of individual injury (RIndInj) has been estimated for each modality and defined as the practical exposure time before an injury occurs, in relation to the number of times that an athlete participates in competition until there is an injury.

$$
\text { RIndInj }=\operatorname{Pext} \overline{\mathrm{x}} / \mathrm{N}^{\circ} \text { Injuries }
$$

Finally, the injury index (II) was defined as the ratio between the total Pext and the number of injuries by modality. 
Table 1 Number of participants

\begin{tabular}{lccccccccc}
\hline & $\begin{array}{c}\text { Ice } \\
\text { hHockey }\end{array}$ & $\begin{array}{c}\text { Alpine } \\
\text { sSkiing }\end{array}$ & Snowboarding & $\begin{array}{c}\text { Freestyle } \\
\text { sSkiing }\end{array}$ & Figure sSkating & $\begin{array}{c}\text { Short tTrack sSpeed } \\
\text { sSkating }\end{array}$ & Curling & Total \\
\hline Women & 144 & 70 & 66 & 39 & 50 & 44 & 46 & 459 \\
Men & 238 & 104 & 86 & 77 & 48 & 50 & 47 & 650 \\
Total & 382 & 174 & 152 & 116 & 98 & 94 & 93 & 1109 \\
\hline
\end{tabular}

$$
\mathrm{II}=\mathrm{Pext} / \mathrm{N}^{\circ} \text { Injuries }
$$

The II would be established as the practice time (h) that elapsed before an injury took place. It should be noted that the lower the relative number we obtain from this equation, the greater the risk of injury will be. We have calculated a $95 \%$ CI to determine the minimum and maximum exposure times, in which it is $95 \%$ likely that an injury occurs.

Table 1 shows the number of registered athletes in all the different sport modalities. One thousand one hundred and nine participants took part including both sexes. The sport in which there was the greatest number of participants was ice hockey (382; 144 women; 238 men). The modality with the least number of participating athletes was curling (93; 46 women, 47 men).

\section{RESULTS}

Ice hockey presents the greatest total Pext during all the competition (97.3 hours) and the greatest average Pext (each player was exposed to the game for $0.247 \pm 0.008$ hours; women: $741,0.206 \pm 0.009$ hours; men: 978, $0.272 \pm 0.008$ hours). Freestyle skiing modality had the lowest total and average time of practical exposure $(0.012 \pm 0.001$ hours; women: 42, $0.012 \pm 0.001$ hours; men: 41, $0.012 \pm 0.001$ hours) (table 2).

There were 68 injuries (6.13\%). The most harmful disciplines were: alpine skiing and ice hockey (18 injuries each; $26.47 \%$ of all injuries), followed by snowboarding (11 injuries; 16.17\%) and freestyle skiing (10 injuries; 14.7\%). The disciplines that caused fewer injuries were curling (five injuries; $7.4 \%$ ), short track speed skating (three injuries; $4.4 \%$ ) and figure skating (three injuries; 4.4\%). Men's snowboarding produced the highest incidence of injuries (11 injuries; 12.79 per each 100 participants), whereas women's snowboarding did not produce any. Although alpine skiing produced 18 injuries, this only meant injury in 10.57 per each 100 participants in this speciality. A percentage of 1.02 of men and $4 \%$ of women were injured in figure skating. There were no injuries in short track speed skating for women (table 3 , figure 1).

The relationship between exposure time and II shows that freestyle skiing showed the shortest time of exposure (0.31 hours) before suffering an injury. There were no injuries in snowboarding and short track speed skating for women, so the exposure times indicated (3.62 and 9.72 hours, respectively) were not sufficient to cause any injury. Therefore, it is not

Table 2 Total time (seconds) and average time (seconds) of practical exposure

\begin{tabular}{|c|c|c|c|c|c|c|c|}
\hline & Ice hHockey & Curling & $\begin{array}{c}\text { Short tTrack } \\
\text { Speed } \\
\text { Skating }\end{array}$ & Alpine Skiing & Figure Skating & Snowboarding & $\begin{array}{c}\text { Freestyle } \\
\text { Skiing }\end{array}$ \\
\hline $\begin{array}{l}\text { Total } \\
\text { practical } \\
\text { exposure } \\
\text { time (hours) }\end{array}$ & 97.33 & 34.49 & 29.67 & 18.03 & 11.14 & 8.14 & 3.18 \\
\hline Women & 31.17 & 14.42 & 9.73 & 7.01 & 7.43 & 3.62 & 0.95 \\
\hline Men & 66.17 & 17.07 & 19.94 & 11.02 & 3.71 & 3.71 & 2.23 \\
\hline $\begin{array}{l}\text { Average } \\
\text { practical } \\
\text { exposure } \\
\text { time (hours) }\end{array}$ & $0.247 \pm 0.008$ & $0.038 \pm 0.003$ & $0.049 \pm 0.004$ & $0.032 \pm 0.002$ & $0.058 \pm 0.006$ & $0.014 \pm 0.002$ & $0.012 \pm 0.001$ \\
\hline Women & $0.206 \pm 0.009$ & $0.039 \pm 0.003$ & $0.041 \pm 0.003$ & $0.035 \pm 0.003$ & $0.057 \pm 0.006$ & $0.015 \pm 0.002$ & $0.012 \pm 0.001$ \\
\hline Men & $0.272 \pm 0.008$ & $0.038 \pm 0.002$ & $0.054 \pm 0.004$ & $0.029 \pm 0.002$ & $0.059 \pm 0.006$ & $0.014 \pm 0.002$ & $0.012 \pm 0.001$ \\
\hline
\end{tabular}


Table 3 Number and percentage of injury by speciality and sex

\begin{tabular}{|c|c|c|c|c|c|c|c|c|}
\hline \multicolumn{9}{|c|}{ Injuries by speciality } \\
\hline Injured & $\begin{array}{l}\text { Alpine } \\
\text { skiing }\end{array}$ & $\begin{array}{c}\text { Ice } \\
\text { hockey }\end{array}$ & Snowboarding & $\begin{array}{l}\text { Freestyle } \\
\text { skiing }\end{array}$ & Curling & Figure skating & $\begin{array}{l}\text { Short track speed } \\
\text { skating }\end{array}$ & Total \\
\hline Women & 7 & 7 & 0 & 3 & 3 & 2 & 0 & 22 \\
\hline Men & 11 & 11 & 11 & 7 & 2 & 1 & 3 & 46 \\
\hline $\begin{array}{l}\text { Total } \\
\text { injuries }\end{array}$ & 18 & 18 & 11 & 10 & 5 & 3 & 3 & 68 \\
\hline $\begin{array}{l}\text { Injuries } \\
(\%)\end{array}$ & 26.47 & 26.47 & 16.17 & 14.7 & 7.35 & 4.41 & 4.41 & 100 \\
\hline \multicolumn{9}{|c|}{ Injuries per each 100 participants } \\
\hline $\begin{array}{l}\text { Women } \\
(\%)\end{array}$ & 10 & 4.86 & 0 & 7.69 & 6.52 & 4.00 & 0 & 4.79 \\
\hline Men (\%) & 10.57 & 4,62 & 12.79 & 9.09 & 4.25 & 1.02 & 6.00 & 7.07 \\
\hline Total (\%) & 10.34 & 4.71 & 7.23 & 8.62 & 5.38 & 3.06 & 3.19 & 6.13 \\
\hline
\end{tabular}

possible to determine a total II for these specialities. Table 4 indicates the II or the relationship between the total Pext and the number of injuries by modality.

The most frequent injuries were blunt traumas (21; $30.88 \%$; 6 in women and 15 in men), joint sprains (16; $23.52 \%$; 5 in women and 11 in men) and blunt subsection traumas with open wounds $(8 ; 11.76 \% ; 3$ in women and 5 in men). Men show a higher incidence of injury $(46 ; 67.64 \%$ ) except in curling (3 injuries in women and 2 in men) and in figure skating (2 in women and 1 in men) (table 5). The head traumas, with and without loss of consciousness, were valued by the medical specialists according to the Glasgow Coma Scale.

The head, shoulder and right hand were the anatomical locations that suffered the most injuries (nine injuries, $13.23 \%$ ), followed by left ankle and knee (seven injuries; 10.29\%). A percentage of 47.1 of injuries (32 injuries) affected the right side of the body, $26.4 \%$ to the left side (18 injuries) and another $26.4 \%$ to head, neck and trunk (18 injuries) (table 6).

\section{Surgical interventions}

One surgery was performed on a female ice hockey athlete with an acromioclavicular dislocation. A female alpine skiing athlete, who suffered a right knee anterior cruciate ligament tear, deferred surgical treatment because she decided to be operated on in her country of origin.

Although it was not included in athletes' statistics, an ice hockey referee suffered a blunt subsection trauma on the right hand while he was warming up before a match, which produced a tear in a section of the third finger extensor tendon and required surgical intervention.
Figure 1 Percentage of injuries by modality

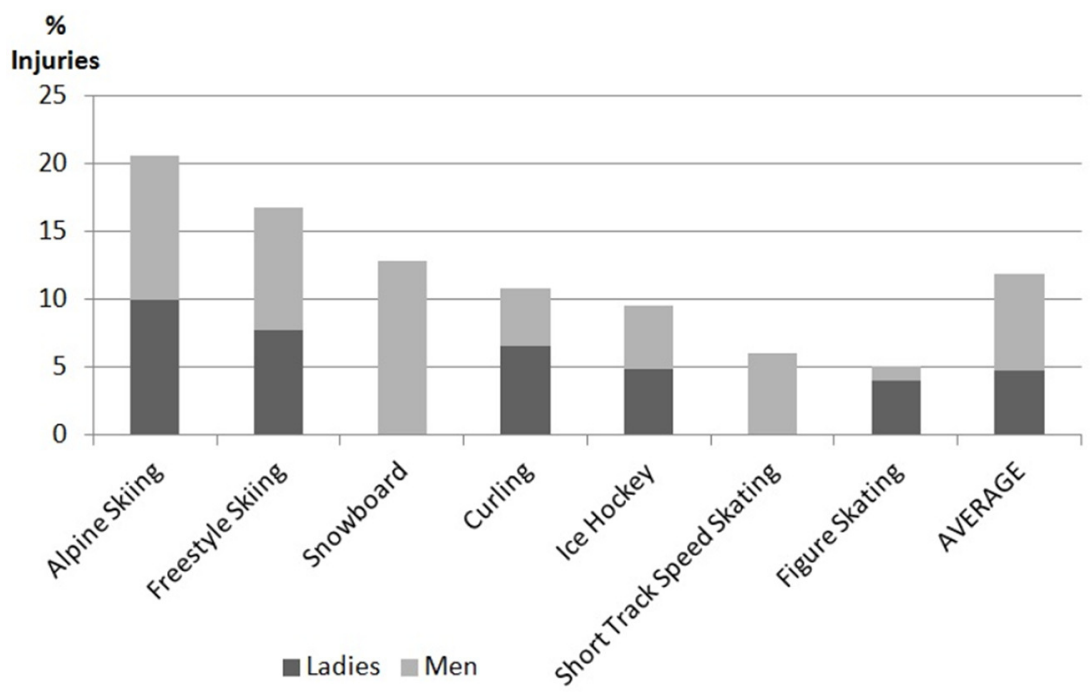


Table 4 Injury index (II) by speciality and sex

\begin{tabular}{llll}
\hline (h)(CI) & Ladies Women's II (hours $(95 \%$ CI)) & Men' s II (hours ((95 \% CI)) & Global II (hours (95 \% CI)) \\
\hline Alpine skiing & $1.22(0.06$ to 1.16$)$ & $0.86(0.04$ to 0.81$)$ & $1.00(0.05$ to 0.99$)$ \\
\hline Snowboarding & $>3.62$ & $0.41(0.02$ to 0.38$)$ & $>0.73$ \\
\hline Freestyle skiing & $0.39(0.01$ to 0.37$)$ & $0.28(0.01$ to 0.27$)$ & $0.31(0.01$ to 0.30$)$ \\
\hline Figure skating & $2.90(0.14$ to 2.75$)$ & $5.33(0.26$ to 5.06$)$ & $3.71(0.18$ to 3.52$)$ \\
\hline Curling & $5.80(0.29$ to 5.51$)$ & $8.53(0.42$ to 8.10$)$ & $6.89(0.34$ to 6.5$)$ \\
\hline Ice hockey & $4.45(0.22$ to 4.22$)$ & $6.01(0.30$ to 5.71$)$ & $5.40(0.27$ to 5.13$)$ \\
\hline Short track speed skating & $>9.72$ & $6.64(0.33$ to 6.31$)$ & $>9.88$ \\
\hline
\end{tabular}

\section{Hospital admissions}

Hospital admissions include two cases of head trauma without loss of consciousness (a snowboard male and a freestyle skiing female practitioners), one case of head trauma with loss of consciousness (a man from alpine skiing) and one case of facial trauma (a man from ice hockey). A hospital observation lasting 24 hours was undertaken in all cases.

\section{Illnesses treated}

Medical services gave assistance to nine athletes $(0.81 \%)$ suffering some kind of non-traumatic illness: stomach flu 1; lipothymy 1; earache 1; headache 2; tonsillitis 1; friction burn 1; insect bite 1 and intestinal parasites 1 . The athlete who suffered stomach flu (alpine skiing) had to be admitted to hospital for his treatment.

\section{DISCUSSION}

In the 2015 Universiade, $6.13 \%$ of the participants suffered some kind of injury or disease. We have registered 68 cases of injuries of which the most harmful sport modalities were alpine skiing and snowboarding. In Torino 2006 Winter Olympic Games, medical attention was given to athletes a total of 330 times, the modalities of skeleton, bobsleigh, alpine skiing, snowboarding and freestyle skiing being those which had the highest prevalence. ${ }^{14}$ The number of participants was 2508, whereas 2015 Universiade involved 1109 participants. However, the different types of specialities and the absence of more harmful specialities such as skeleton, bobsleigh or jumps, which were not held at the 2015 Universiade, have limited the amount of these injuries, as it is suggested by others studies. ${ }^{14}$

We have determined that the incidence of injuries in 2015 Universiade is lower with respect to those registered at the Youth Olympic Winter Games in Innsbruck in $2012^{6}$ in which $11 \%$ of athletes suffered some kind of an injury and $9 \%$ a disease. In London 2012 Summer Olympic Games, 11\% of the athletes suffered some injury during the competition and a total of $7 \%$ illness, but there were also substantial variations in the incidence of injuries among different modalities. ${ }^{15}$ This would be comparing youth athletes with elite athletes, due to the fact that there is not many references with this population, hence the relevance of this study. It must be taken into account that cross-country skiing, Nordic combined, ski jumping and biathlon competitions did not take place in the city of Granada but rather in Slovakia and as a result these injuries and diseases have not been considered in this study due to the fact that we could not access the Slovakian medical committee's information. This may have resulted in differences in the observed total injuries with respect to other events. Therefore, we have differentiated the injuries by speciality to be able to relate our data with the results of other studies.

In the 2015 Universiade, the incidence of injuries and diseases varies between the different modalities, resulting in disciplines that have come to produce a high number of injuries (alpine skiing and snowboarding, both with $26.4 \%$ of all injuries) as opposed to other sport disciplines that have been shown to have less risk of injury (curling and short track speed skating, $4.41 \%)$. Men's snowboarding is the sport that had a higher incidence of injuries for every 100 participants (12.79 injuries for every 100 participants) compared with Snowboarding in women in which there were no injuries. Men's alpine skiing showed an incidence of 1057 injuries/100 participants; freestyle skiing 9.09; men's figure skating only showed 1.09 and no injury was registered in the women's short track speed skating, despite being a very explosive modality, dynamic and involving physical contact.

These differences in the incidence of injuries among specialities of winter sports may be due to differing exposure times, environmental conditions and regulation. Even within the same speciality, there are different modalities that make comparison between the incidence of injuries difficult. During the 2015 Universiade, alpine skiing competitions included slalom and super giant, whereas in snowboarding, the specialities were slopestyle, cross, halfpipe, and parallel giant slalom, each with very different exposure times, technical and tactical difficulties, affecting the occurrence of injuries ${ }^{13}$ that were not dealt with in this study. 
Table 5 Type of injuries by sport and sex

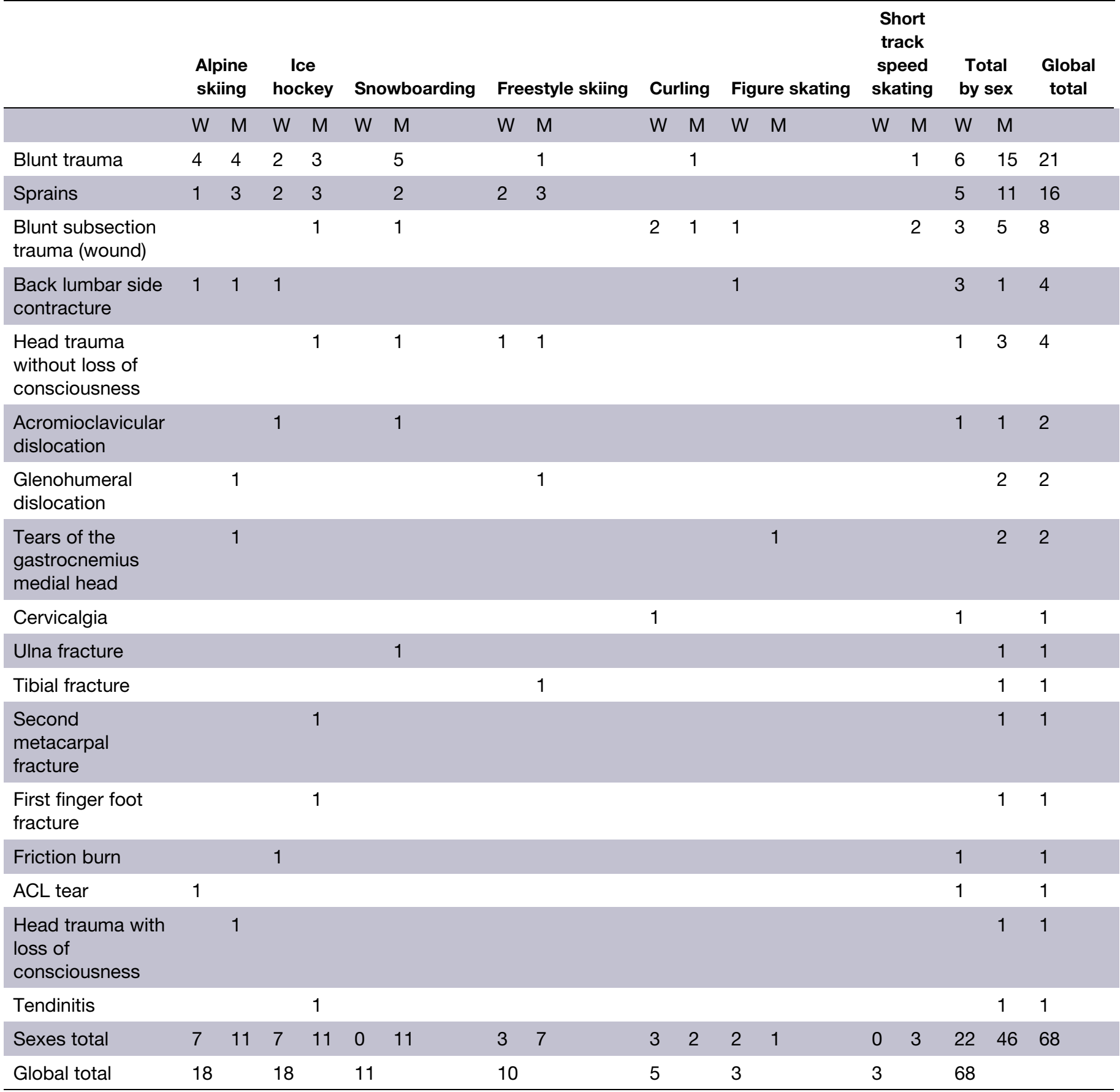

$\mathrm{M}$, men; W, women.

The prevalence of injuries in ice hockey during international competitions tends to be higher than in other sport modalities, ${ }^{16}$ as opposed to our study, in which the modality of ice hockey has not had the highest II. There are many factors in this sport that are used to reduce the possibility of suffering injuries, for example the characteristics of the rink, the edges and flexibility of the protective crystals, helmet, gloves, voids, and others. ${ }^{16}$ In women's ice hockey, the regulatory prohibition of making charges during play is also a factor that limits the number of injuries.

We have used an II that relates the exposure time expressed in hours with the number of injuries suffered. So, in freestyle skiing, there was an injury every 0.31 hours. However, in women's snowboarding, there was no injury in 3.62 nor in 9.72 hours of competition held in women's short track speed skating. Therefore, we cannot know what the real II is in these specialities. Rønning et $a l^{17}$ established an II related to 
Table 6 Anatomical localisation of injuries by sport and sex

\begin{tabular}{|c|c|c|c|c|c|c|c|c|c|c|c|c|c|c|c|c|c|}
\hline & \multicolumn{2}{|c|}{$\begin{array}{l}\text { Alpine } \\
\text { skiing }\end{array}$} & \multicolumn{2}{|c|}{$\begin{array}{c}\text { Ice } \\
\text { hockey }\end{array}$} & \multicolumn{2}{|c|}{ Snowboarding } & \multicolumn{2}{|c|}{ Freestyleskiing } & \multicolumn{2}{|c|}{ Curling } & \multicolumn{2}{|c|}{ Figure skating } & \multicolumn{2}{|c|}{$\begin{array}{c}\text { Short } \\
\text { track } \\
\text { speed } \\
\text { skating }\end{array}$} & \multicolumn{2}{|c|}{$\begin{array}{l}\text { Total } \\
\text { by sex }\end{array}$} & \multirow{2}{*}{$\begin{array}{c}\begin{array}{c}\text { Global } \\
\text { total }\end{array} \\
(N+\%)\end{array}$} \\
\hline & W & $M$ & W & $\mathrm{M}$ & W & $\mathrm{M}$ & W & $M$ & $W$ & $M$ & $W$ & $M$ & W & $M$ & W & $M$ & \\
\hline Head & & 1 & & 3 & & 3 & 1 & 1 & & & & & & & 1 & 8 & $9(13.23)$ \\
\hline $\begin{array}{l}\text { Right } \\
\text { shoulder }\end{array}$ & 1 & 1 & 2 & & & 4 & & 1 & & & & & & & 3 & 6 & 9 (13.23) \\
\hline Right hand & & & 2 & 2 & & & & & 2 & 1 & & & & 2 & 4 & 5 & $9(13.23)$ \\
\hline Left knee & 3 & 3 & & 1 & & & & & & & & & & & 3 & 4 & $7(10.29)$ \\
\hline Left ankle & 1 & & & 1 & & & 2 & 3 & & & & & & & 3 & 4 & $7(10.29)$ \\
\hline $\begin{array}{l}\text { Back lumbar } \\
\text { side }\end{array}$ & 1 & 1 & & 1 & & 1 & & & & 1 & 1 & & & & 2 & 4 & $6(8.82)$ \\
\hline Right knee & & 3 & & 1 & & 1 & & & & & & & & & 0 & 5 & $5(7.35)$ \\
\hline $\begin{array}{l}\text { Right } \\
\text { forearm }\end{array}$ & & & 1 & & & 1 & & & & & & & & 1 & 1 & 2 & $3(4.41)$ \\
\hline Right ankle & & & & 1 & & 1 & & 1 & & & & & & & 0 & 3 & $3(4.41)$ \\
\hline $\begin{array}{l}\text { Cervical } \\
\text { spine }\end{array}$ & & & 1 & & & & & & 1 & & & & & & 2 & 0 & $2(2.94)$ \\
\hline Right leg & & 1 & & 1 & & & & & & & & & & & 0 & 2 & $2(2.94)$ \\
\hline Left hand & & & 1 & & & & & & & & 1 & & & & 2 & 0 & $2(2.94)$ \\
\hline Left leg & & & & & & & & & & & & 1 & & & 0 & 1 & $1(1.47)$ \\
\hline $\begin{array}{l}\text { Right } \\
\text { hemithorax }\end{array}$ & & & & & & & & 1 & & & & & & & 0 & 1 & $1(1.47)$ \\
\hline Left foot & 1 & & & & & & & & & & & & & & 1 & 0 & $1(1.47)$ \\
\hline Right heel & & 1 & & & & & & & & & & & & & 0 & 1 & $1(1.47)$ \\
\hline Sexes total & 7 & 11 & 7 & 11 & 0 & 11 & 3 & 7 & 3 & 2 & 2 & 1 & 0 & 3 & 22 & 46 & $68(100)$ \\
\hline Global total & 18 & & 18 & & 11 & & 10 & & 5 & & 3 & & 3 & & 68 & & \\
\hline
\end{tabular}

M, men; W, women.

distance in skiing or recreational snowboarding, determining the number of injuries per every $100000 \mathrm{~km}$. His data suggested an incidence of injury requiring treatment in the hospital three to four times higher among the snowboarding practitioners than among alpine and telemark skiers. This index is not applicable to indoor specialities in 2015 Universiade, so we could not use it. Nor is it possible to compare with studies that have determined the incidence of injuries in World Cup telemark skiing ${ }^{18}$ because this discipline is based on having free heel, which makes it many more difficult in practice than the alpine disciplines practised in 2015 Universiade and refers to an entire season or to the incidence of injuries in relation to the number of runs. ${ }^{19}$

Besides blunt head trauma (nine injuries; $13.23 \%$ of all injuries), there is a clear predominance of injuries in the right upper limbs (right shoulder: nine injuries; 13.23\%; right hand: nine injuries; $13.23 \%$ ) especially injuries caused by ice hockey (six injuries) in which the management of the stick is predominantly righthanded subjects. Then, the left lower limb injuries stand out (seven left knee injuries: 10.29\%; seven left ankle injuries: $10.29 \%$ ) due to the predominance of support in the left lower limbs in right-handed subjects.

\section{Limitations}

It is necessary to determine more specifically the total Pext of each athlete. Sport modality should also be related with level of achievement in each event, as the most experienced athletes reach the finals, whereas the less technically or physically gifted athletes are eliminated early. Thus, adjustments to take into account the participation of athletes according to the stage in which they are knocked out or the stage of the tournament that they reached could obtain a more accurate quantification of times in which the athletes have been competing. 


\section{CONCLUSIONS}

A total of 68 injuries (6.13\% of injured athletes) and 9 diseases $(0.81 \%)$ occurred in 2015 Universiade. These rates are lower than those recorded in other winter sports competitions.

Freestyle skiing is the modality at greatest risk of exposure of injury (0.31 hours). Short track speed skating showed the greatest exposure time before suffering an injury (9.88 hours). Women's snowboarding and women's short track speed skating did not record any injuries.

Men suffer more injuries, except for figure skating, curling and slightly in ice hockey. Men have more Pext before suffering an injury in all modalities, except for figure skating, curling and ice hockey.

The head, right shoulder and right knee were the anatomical areas with the most injuries (13.23\% each area). It is very difficult to estimate of the risk of injury in winter sports, and deeper studies are needed on the environmental, personal, technical and tactical causes that may result in more injuries.

In the future, preventive measures should be taken into account to combat the occurrence of injuries and diseases in competitions. New studies are needed to research the main injuries in each of the specialities and their impact on the young athlete's future, especially in lower level competitions to understand the mechanisms and risk factors before impinging on prevention measures. ${ }^{19}$ However, different type of sport specialities, risk factors, environmental exposures, and tactical and technical conditions make it necessary to carry out more specific studies of each speciality.

Contributors MAGV Chief Medical Officer of the University of Granada 2015 Winter sports. JCCM Responsible for records of injuries and illnesses. Coordinator of the working group. ACC, Responsible for drafting the document, writing,translation. JCCC, Responsible for the preparation of statistical data. FLPM, Responsible for data collection practice in Ice Hockey exhibition, Curling and Alpine Skiing. GCR, Responsible for data collection practice exposure Snowboarding and Figure Skating. LMGG, Responsible for data collection of practical exposure in Short Track Speed Skating and Freestyle Skiing. All authors contributed to refinement of the study protocol and approved the final manuscript.

Competing interests The study's authors declare that they have no conflict of interest and that its objectives have been strictly scientific.

Ethics approval The approval of the ethic committee of Granada University has been also obtained (with registration number 22/CEIH/2015).

Provenance and peer review Not commissioned; externally peer reviewed.

Data sharing statement The data have been kept by the Chief Medical Officer Winter Universiade Sports Granada 2015 and have not been exchanged with any person or entity.
Open Access This is an Open Access article distributed in accordance with the Creative Commons Attribution Non Commercial (CC BY-NC 4.0) license, which permits others to distribute, remix, adapt, build upon this work noncommercially, and license their derivative works on different terms, provided the original work is properly cited and the use is non-commercial. See: http:// creativecommons.org/licenses/by-nc/4.0/

(c) Article author(s) (or their employer(s) unless otherwise stated in the text of the article) 2017. All rights reserved. No commercial use is permitted unless otherwise expressly granted.

\section{REFERENCES}

1. Risks and benefits of youth sport specialization: perspectives and recommendations. Pediatr Exerc Sci https://apps.webofknowledge. $\mathrm{com} /$ full_record.doproduct $=$ WOS\&search_mode $=$ GeneralSearch\&qid $=1 \&$ SID $=$ U1 o9ZKK4omkOY4CVvMI\&page $=1 \&$ doc $=1$ (accessed 19 Oct 2015).

2. Emery CA. Risk factors for injury in child and adolescent sport: a systematic review of the literature. Clin J Sport Med 2003;13:256-68.

3. Engebretsen L, Steffen K, Alonso JM, et al. Sports injuries and illnesses during the winter olympic games 2010. Br J Sports Med 2010;44:772-80.

4. Clarsen B, Rønsen O, Myklebust G, et al. The oslo sports trauma research center questionnaire on health problems: a new approach to prospective monitoring of illness and injury in elite Athletes. $\mathrm{Br} \mathrm{J}$ Sports Med 2014;48:754-60.

5. Hanstad DV, Rønsen O, Andersen SS, et al. Fit for the fight? illnesses in the norwegian team in the vancouver olympic games. $\mathrm{Br}$ $J$ Sports Med 2011:45:571-5.

6. Blank C, Schamasch P, Engebretsen L, et al. Medical services at the first winter youth olympic games 2012 in Innsbruck/Austria. Br J Sports Med 2012;46:1048-54.

7. Flørenes TW, Bere $T$, Nordsletten $L$, et al. Injuries among male and female world cup alpine skiers. Br J Sports Med 2009;43:973-8.

8. Flørenes TW, Heir S, Nordsletten L, et al. Injuries among world cup freestyle skiers. Br J Sports Med 2010;44:803-8.

9. Flørenes TW, Nordsletten L, Heir S, et al. Injuries among world cup ski and snowboard Athletes. Scand J Med Sci Sports 2012;22:58-66.

10. Torjussen J, Bahr R. Injuries among elite snowboarders (FIS snowboard world cup). Br J Sports Med 2006;40:230-4.

11. Westin M, Alricsson M, Werner S. Injury profile of competitive alpine skiers: a five-year cohort study. Knee Surg Sports Traumatol Arthrosc 2012;20:1175-81.

12. Palmer-Green D, Elliott N. Sports injury and illness epidemiology: great britain olympic team (TeamGB) surveillance during the Sochi 2014 winter olympic games. Br J Sports Med 2015;49:25-9.

13. Soligard T, Steffen K, Palmer-Green D, et al. Sports injuries and illnesses in the sochi 2014 olympic winter games. Br J Sports Med 2015; $49: 441-7$

14. Piat SC, Minniti D, Traversi D, et al. Torino 2006 winter olympic games: highlight on health services organization. J Emerg Med 2010;39:454-61.

15. Engebretsen L, Steffen K, Alonso JM, et al. Sports injuries and illnesses during the winter olympic games 2010. Br J Sports Med 2010;44:772-80.

16. Tuominen M, Stuart MJ, Aubry M, et al. Injuries in men's international ice hockey: a 7-year study of the International Ice Hockey Federation Adult World Championship Tournaments and Olympic Winter Games. Br J Sports Med 2015;49:30-6.

17. Rønning R, Gerner T, Engebretsen L. Risk of injury during alpine and telemark skiing and snowboarding. the equipment-specific distancecorrelated injury index. Am J Sports Med 2000;28:506-8.

18. Johansen MW, Steenstrup SE, Bere T, et al. Injuries in world cup telemark skiing: a 5-year cohort study. Br J Sports Med 2015;49:453-7.

19. Alonso JM, Edouard P, Fischetto G, et al. Determination of future prevention strategies in elite track and field: analysis of daegu 2011 IAAF championships injuries and illnesses surveillance. Br J Sports Med 2012;46:505-14. 